Boot and Shoe and Allied Trades Research Association on problems relating to the manufacture and utilisation of rubber will undoubtedly develop.

An important feature of the work of the Association is its library and information bureau, which serve the growing needs of all connected with the industry for a source of information and advice over a wide range of subjects. Without the regular issue of the monthly summary of current literature it would be difficult for the industry to keep itself abreast of all the latest developments ; and when to this invaluable intelligence service there is added the issue of periodical circulars summarising the available knowledge on many scientific, technical, and economic subjects and the satisfying of an ever-growing number of inquiries (amounting to 690 in 1931 alone) covering all phases of the rubber industry, it can safely be asserted that the Research Association is rendering to the British industry services that are unsurpassed by the similar associations in Germany and Holland. In addition, a centralised organisation is able to carry out work of this kind much more thoroughly and efficiently than any one firm alone could hope to do, and avoids all the overlapping and duplication of effort which would occur if individual firms maintained their own organisations.

Already the number of cards in the index main. tained by the Association amounts to well over 125,000, and the subject cards alone are increasing by about 14,000 a year. These statistics, however, give little idea of the magnitude of the work involved in cross indexing, and in the course of the work the library and information bureau has evolved its own system of classifying scientific, technical, and commercial information on rubber, based on a generalised decimal notation, although the International Brussels system was rejected on account of serious difficulties it offers in use for rubber information. The value of the work of this section of the Association is further attested by the recognition of the library in 1930 by the Carnegie Trust as an outlier of the National Central Library. The generous grant made in accordance with that recognition has made it possible to expand considerably the library collection, and thus to im. prove further the utility of what is already a fully representative collection of all modern publications and particularly in regard to trade literature.

The above brief outline of the activities of the Association taken from the annual report gives some indication of the many services which the Research Association is rendering to the rubber industry, and illustrates the way in which that research reacts to the direct benefit of the public, as well as the tendency towards co-operative research between different branches of industry. One of the most surprising things in the report is the smallness of the staff with which this extensive and important work is being carried out. When we consider that as yet relatively little is known regarding the nature of rubber or the changes which occur during vulcanisation, apart altogether from the many problems presented by the utilisation of rubber, it is clear that the expansion in the work of the Association, and particularly the extension of systematic fundamental research which is anticipated as a result of the Rubber Industry Bill passing into law, should be of the utmost value and importance to the industry. Its practice cannot but be imperfect when the mechanism of the essential process is incompletely understood. The future of the rubber industry depends upon the wise, continuous, and adequate prosecution and application of scientific research, and the praiseworthy work already carried out by the Research Association indicates the possibilities when the industry as a whole devotes to the support of co-operative research the energy and financial support which it imperatively demands.

\title{
Uses of Empire Timbers*
}

TYNDER the auspices of the Forest Products Research Board of the Department of Scientific and Industrial Research, inquiries are being carried out into the possible uses of Empire timbers. The results of the first year's investigations are given in the annual Report of the Board before us. Under the auspices of the Empire Timber Committee the work was started late in 1929, further facilities for the contemplated research becoming available by the end of last year.

Tests have been undertaken with East African camphor wood from Kenya for cabinet making; walnut and sapeli woods from Nigeria, both for cabinet making; and Meranti tombaga and Keruing timbers from the Federated Malay States, which might displace some of the Philippine timbers on the London market, provided they can be imported at competitive prices. New Zealand silver beech is to be tested for furniture wood at High Wycombe and in the making of rifle stocks at the Small Arms Factory at Enfield. Another subject reported upon is the investigations into the creosoting of British Columbian Douglas fir, since this timber might prove a considerable asset for railway sleepers. So far, Douglas fir timber has proved less easy to creosote than Baltic fir. By adopting the Canadian and American method of what is known as 'incising' over the sleepers, it was found possible to inject as

* Department of Scientific and Industrial Research. Report of the Forest Products Research Board ; with the Report of the Director of
Forest Products Research for the Year 1930 . Pp. vii $+52+10$ plates. (London: H.M. Stationery Office, 1932.) 48. net.

No. 3262, Vor. 129] much creosote into them as the Baltic species will absorb.

The writers of the report comment upon the increased interest of the public in Empire timbers, for use in both Government and private buildings. But the opinion is stressed that the joint work of the Department and the Empire Marketing Board is not by itself sufficient to cover the necessities of achieving a general development and national use of Empire timbers. Unless production and marketing are closely co-ordinated with research, the work of the Board will be impaired. Apart from measures to be taken by the timber trade, it is stated that there is a lack of adequate official machinery for dealing with difficulties in the producing areas; more especially in certain of the tropical regions.

The difficulties, it is urged, could be largely overcome by comprehensive botanical and economic surveys of our forest resources, involving some enlargement of the facilities at the disposal of the Imperial Forestry Institute and the forest services, and by closer liaison and personal touch with the interests concerned in the country of origin. The suggestion of the enlargement of the facilities at the disposal of the forest services is timely at a moment when most of these services are being cut down owing to financial stringency.

The efforts of the departments responsible for the admirable work described in the report here dealt with require the careful consideration of the authorities responsible for forest administration in the various Colonies. 